\title{
Analysis of E-Commerce Model in Transaction Cost Economics Framework
}

\author{
Zhao Duan \\ Information Management Department, HuaZhong Normal University \\ 152 Luoyu Road.whan hubei.P.R.China, 430079 \\ victorduan@hotmail.com
}

\begin{abstract}
This paper introduces the theory and method of Transaction Cost Economics to identify the essence of e-commerce model by explicating its core objective and function. From the correspondence of transactions and governance structures, the author also discusses the design principle of an ecommerce model. The analysis shows that so-called e-commerce model in commercial practice could be identified as non-market governance structure in TCE framework. Also, under the high uncertainty of Internet, to minimize transaction costs, various e-commerce transaction distinguished by different assets specificity and transaction frequency should mutually correspond with governance structures having different expense and function. The analysis attempts to unify the existing definitions and classifications about e-commerce model in a multi-discipline framework, and bring people some new clues for the innovation in e-commerce application. At the same time, this heuristic perspective waits for the comprehensive examinations by further empirical researches.
\end{abstract}

\section{Introduction}

The Transaction Cost Economics developed by O. Williamson [1-13] on the base of R. Coase's [14-15] research, emphasizes transaction's attributes and the correspondences with governance structure. Nowadays, transaction cost economics has been the core theory of organization economics.

There are three key concepts involved in Transaction Cost Economics: assets specificity in the technical issues, bounded rationality hypothesis about the human nature, and opportunism on the behavior aspect. Williamson argued "a transaction occurs when a goods or service is transferred between technologically separable stages" [16]. The attributes of transaction can be identified from three lengths: assets specificity, uncertainty and transaction frequency. Under the bounded rationality

Please use the following format when citing this chapter:

Duan, \%, 2007, in IFIP International Iederation for Information Processing, Volume 25I, Integration and Innovation Orient to E-Socicty Volumel. Wang, W. (Eds), (Boston: Springer), pp. 627-634. 
hypothesis, it takes people high transaction cost to estimate the time and styles of opportunism's occurring and to make precautions. To ensure the proceeding of the transaction and save transaction costs, it is necessary to construct matches between transactions with different attributes and governance structures with different costs and efficiencies. Distinguishing from incentive intensity, administrative control and the contract law regime, the alternative modes of governance structure include market, hybrid and hierarchy. In this framework, transaction could be considered as the most basic and general form of human economic relationship. No matter what simple or complicated e-commerce activities, transaction could be taken into account as a basic analyzing unit.

Compared with traditional spot market, Internet involves higher uncertainty and more opportunism. Under this circumstance, the neoclassic contracts is hard to be applied to govern all e-commerce transaction relationships, only three choices can be made: aborting the transaction; integrating into organization internal transaction; or depending on certain hybrid governance structure that can not only ensure the relevant modifications of the contract ex ante with the continuing and the extending of the transactions, but also be able to defend opportunism and to save transaction cost. Hence, whether an e-commerce activity can realize and bring value for transactors depends on whether a kind of effective governance structure can be built to coordinate the mutual economic relationships between transactors. Actually socalled e-commerce model could be considered as a kind of exterior exhibition of governance structure in commercial practice. In this way, some new approaches might be offered for e-commerce practitioners by using the theory and methods of transaction cost economics to study the attributes of various e-commerce transactions, attributes of e-commerce transactions' governance structure, and researching their mutual correspondence.

Issues of two aspects will be discussed in this paper: part one will identify the essence and connotation of e-commerce model from the Transaction Cost Economics paradigm; part two will analyze the design principle of e-commerce models to correspond the attributes of e-commerce transaction.

\section{Identification of E-Commerce Model from Transaction Cost Economics Paradigm}

At present, there is no unified cognition for the definition and classification of ecommerce model yet. Except B2B, B2C and C2C models, many scholars such as Paul Timmers [17], Paul Bambury [18], Allan Afuah \& Christopher Tucci [19], Magali Dubosson-Torbay [20], Peter Weil [21] and B. Mahadevan [22] etc. came up with nearly 20 kinds of various definitions and classifications. However, none of them is evaluated as perfectly complete and systematic.

Generally speaking, e-commerce model refers to the manners and approaches used to carry out business online. From the transaction cost economics paradigm, it could be considered as the governance structure constructed by a serial of contractual relationship among e-commerce transactors in order to ensure the value brought for the transactors. Specifically, two aspects' connotations are involved: one part is the incomplete contracts established ex ante by transactors, namely only a restrictive 
contractual framework is made to explain the business principle, performance program, mechanism of solving conflicts, and rights' attribution of the transactors etc; while the other part is the contract performance mechanism established to ensure the transaction take place, continue and produce value.

E-commerce transactions carry through partially or entirely online. Three reasons cause a complete contracts not able to be established by the transactors: (1) Because of the bounded rationality and asymmetric information, transactors are hard to estimate exactly plenty of occasional and random unborn events; (2) Even if those haphazards are exactly estimated and could be put into the contract clauses with no controversial wordings, the separation of the e-commerce transactors by Internet would make the bargaining costs pretty high; (3) After the establishment of the contract, there are still various difficulties to examine the execution of the contract clauses, even a third-party is involved, the cost of testifying who breaks the contracts and measure the loss would be very high. Hence, even an incomplete contracts exists lot of trouble of ex post adjustments, transactors establish an incomplete contract is still accord with a rational expectation. However, another problem is, incomplete contract would have to face with sorts of "post-contractual opportunistic behavior's hold-ups" [23]. For the transactor who involved transaction-specific assets, there exists risk that another side may depredate "the appropriable specialized quasi-rents " [23] from specific assets by using dishonest and deceitful means. So the side involving assets specificity must require for certain mechanism to minimize the risk of the hold-ups and to ensure the continuity of the transaction.

In the applications of e-commerce, various combinations of incomplete contracts and performance ensure mechanisms emerged through the bargaining between transactors or under unilateral authority, among the mutual competition, bring out some transplantable and imitable models, contribute the functions of crafting order, mitigating conflict and realizing mutual gains.

The Usual governance structures in the e-commerce include bilateral governance structure, trilateral governance structure, hierarchy and "contract enforcement mechanism" [24]. A governance structure may present as a formal and legally executable contractual form, or as a private arrangement outside law.

The contributions of identifying e-commerce model from transaction cost economics paradigm lies in the following three aspects: (1) In the research, transaction is regarded as the basic analysis unit, which can decrease the analysis complexity of e-commerce activities involved participants' roles, alternate relationships, product characteristic, behaviors and benefit sources etc; (2) Ecommerce activities value source is attributed to the saving of the transaction cost and the continuity of the transaction, which clears an important direction of the innovation of e-commerce application; (3) E-commerce model is considered as a kind of governance structure, which can transfer the question of seeking an appropriate model into a question of seeking the effective correspondence among various attributes of e-commerce transaction and various governance structure, which can offer some new ideas for the innovation and optimization of e-commerce models. 


\section{The Correspondence of E-Commerce Transaction and Non- Market Governance Structure}

Among the three identification lengths of transaction attributes, Williamson suggested that assets specificity is the most important factor [25]. Assets specificity refers to the attribute that the assets can not be reused for other purpose when it is involved in a specific transaction. For example, when some durable investment is used to support certain transaction, the assets formed during this period has this specificity. If the relative contractual relationship is terminated before the accomplishment of this transaction, the assets would be difficult for other utilities, and a part of sunk cost is involved. Therefore, the more assets specificity is involved in a transaction, the more continuity and harmony of the transaction would be cared about, and the more requirements to establish certain performance ensure mechanism would be brought out.

If no specific asset is involved in e-commerce, both sides of transactors can find other trade partners easily. They don't depend to each other, and none of them cares about the continuity of the transaction. Both sides always rules the transaction by the contracts they established ex ante and use court ordering to solve the conflicts ex post. Once the specific assets invested by one side arrives a critical level (use A' to express), the transaction cost of the e-commerce organized and managed by the traditional spot market governance structure will rise significantly, and it becomes necessary to introduce the hybrid governance structure or integration to replace spot market.

In e-commerce activities, the specific assets (use letter A to express) involved in a certain transaction can be scaled in the following formula: $A=(F / q)+S$. " $F$ " represents the specific assets such as human resources, material resources and reputation which a transactor invest in the e-commerce platform serving for all ecommerce transactions; " $q$ " represents the total amount of prospective congener ecommerce transaction; and " $S$ " represents the specific assets correlating with the transaction itself, such as the resources invested for information screening, payment or logistics etc. Different from the traditional spot market, the necessary supportive facilities and the spatial and temporal elements in the e-commerce have decided that at least one side of the transactors can not keep away from some specific assets investment. In addition, the higher uncertainty and asymmetric information will increase transactors' sensitivity about contractual haphazards and cast enough influence on their decision-making and adjusting, which will put ulteriorly lower the lever of $A^{\prime}$. Therefore, owing to the general existence of certain unevadable specific assets over $A^{\prime}$, nearly all of e-commerce transactions should be corresponding with non-market governance structures. It can partly explain why people feel the business way in the Internet market is different from that in the spot market. 


\section{The Correspondences of the E-Commerce Models with Various Attributes of E-Commerce Transaction}

Uncertainty and transaction frequency are two others lengths to identify transaction attribute. Uncertainty comes from the asymmetric information between transactors, the impossibility to forecast all haphazard at ex ante, and the obstacle of high costs of forecasting or making precaution measure in contract. The meaning of uncertainty is to make people's choice become necessary, when a transaction is influenced by high uncertainty, people have to make choices between different governance structures under the principle of minimum transactions costs. The virtuality of transactor's identity, complexity during the course of transaction and the asymmetric information in the e-commerce activities make both transactors have to face a higher challenge of uncertainty from the environment and transaction itself, which increase their requirements about the flexibility of governance structure.

Transaction frequency refers to the rate of occurrence of repetitive transactions. It has direct impact on the relative value of transaction cost instead of absolute value. Though transaction cost decrease with the ascending of frequency, the cost can not reduce infinitely and approach to zero. The establishment and operation of a governance structure exists expense. To what extent can this expense be covered depends on the occurrence frequency of the transaction under such governance structure. More frequently transactions happen; easier expense of governance structure can be covered. Therefore, for an e-commerce transaction involving assets specificity and high uncertainty, frequency has direct impact on the mode of governance structure.

In the following analysis, uncertainty in e-commerce will be entirely supposed high enough and as a fixed factor, the attributes of e-commerce transaction will be partitioned as three main circumstances basis on the intensity and extension of assets specificity. In each circumstance, design principles of e-commerce model will be differentiated by the transaction frequency.

\subsection{Both sides involving highly assets specificity (A1 $>A 1$ ' $\cap A 2>A 2$ ')}

In such circumstances, once the transaction is interrupted the establishment of a new transaction relation will cost much. Both sides of transactors press for the stability of relation and continuance of transaction.

If the transaction frequency is very high, the expense of establishing a special organization to manage repetitive transactions can be covered easily, building of integration governance structure (hierarchy) would become cost-efficient, such as intranet e-commerce model.

If the frequency is low, the expense of integration are hard to be covered, the ex ante incomplete contract will need to be re-negotiated and re-adjusted frequently, and the post-contractual haphazard may cause endless bargaining and loss of time and money, even high risks of conflict. If transactors haven't mutual dependence relation in resource control, both sides would be unwilling to make specific asset investment ex ante, so transaction will be hard to realize, and the lack of investment will cause efficiency loss; but if one side has power of resource control, he could 
constitute "in-or-out" or "all-or-none" clauses in incomplete contract ex ante to increase the possibilities of transaction.

\subsection{One side involving assets specificity, another not. ( $A 1>A 1$ ' $\cap \mathrm{A} 2<\mathrm{A2}$ ')}

In such circumstances, both sides have different attitudes towards the continuance and harmony of transaction. The side involving assets specificity will press for certain "weapon" to defend potential hold-ups of appropriable specialized quasi-rents from the other side. Therefore, the core of designing e-commerce model is to set up possible contract self-enforcement mechanism to defend opportunism.

One adoptable way is to add personal penalty clauses on the observable business partner who has the tendency of breach of faith. Penalty clauses usually include two aspects: one is the threat of compensation in case of the transaction being interrupted by opportunism. If the quasi-rent coming from prospective opportunistic behaviors is less than the amount of compensation according to the clauses, hold-ups could be defended and the contract would be performed implicitly; the other is the devalue of reputation, which can bring the opportunist higher transaction costs in future business, so that reduces tendency of cheating.

Presently, the difficulties of transactor's identity investigation in e-commerce and lack of relevant legal regulation may cause the opportunist to escape from the penalty, so some other measures usually need to be combined for improving executing effect. If the transaction frequency is high, the side not involving assets specificity might temporarily abandon the option of hold-ups for a long-term interest, and once he can estimate exactly the amount of unborn transactions, opportunistic behaviors may take place in the ultimate transaction. In this case, for the side involving assets specificity, one alternative way is to combine personal penalty clauses with emotional attachment by the power of social routines, morality and spirit to defend opportunism; and another way is to use strategy of multi-part pricing according to the transaction accumulative times, which could induce the other side keep increasing the estimated amount of the future transaction and delaying opportunistic actions.

If the transaction frequency is low, penalty clauses should be combined with certain necessary legally retroactive measures, such as registration and authentication of verifiable information and setting reputation classification as entry barrier, etc.

\subsection{Both sides involving certain assets specificity ( $A 1>A 1$ ' $\cap A 2>A 2$ ')}

In such circumstances, both sides will focus on the continuance of transaction and wish to establish some kind of ensure mechanism to reduce the uncertainty in transaction. It is the dominant circumstances in present e-commerce activities.

If the transaction frequency is low, the expense of establishing a special organization is hard to be covered; introducing third parties into a transaction is appropriate. This model is very popular in current e-commerce, for example, many ecommerce activities carry out through e-market platform provider, e-broker website, e-agency and online auction, or by using third-party security authentication, thirdparty payment system and logistics, etc. 
If the transaction frequency is high, a bilateral governance structure will become more cost-efficient. The fashions of bilateral governance structure generally include establishing long-term contract, reciprocity, pledge and placing specific assets mutually. Under this model, both sides could not only keep independent relatively, but also balance transaction risks, make transaction relationship highly stable and sustainable, and increase mutual interests. In current e-commerce, B2B basis on supply-chain is a representative exhibition of this situation.

\section{Conclusion}

The rapid development of e-commerce owes to the saving of transaction cost coming from innovations and applications of computer science and information technology. Meanwhile, the higher uncertainty and opportunism in the Internet increase ex ante and ex post transaction costs from contract process on the other hand. The key of the substitution of e-commerce for traditional spot market, rely on whether we can establish certain corresponding governance structure to effectively organize and manage contractual relationship in e-commerce activities, and to minimize this transaction costs from contract process. Otherwise, the contribution of science and technology would regrettably be partially counteracted by the deficiency of institution.

But in practice, the diversiform and complex appearances of e-commerce model maybe make us be blind to its core objective and function, make us attend to trifles but neglect the essentials. Therefore, identifying e-commerce model as non-market governance structure and emphasizing the correspondence with transaction attributes in TCE framework will probably not be totally accepted by everyone, but if those multi-discipline perspectives could bring some new clues to the e-commerce scholars and practicers, the author's intention has achieved.

\section{Reference}

1. O. Williamson, Markets and Hierarchies: analysis of antitrust implications (Free Press, New York, 1975).

2. O. Williamson, The Economic of Institute of Capitalism (Free Press, New York, 1975).

3. O. Williamson, Comparative Economic Organization: The Analysis of Discrete Structural Alternatives, Administrative Science Quarterly; Vol. 36 Issue 2 (Jun 1991), pp. 269-296.

4. O. Williamson, Transaction Cost Economics and Organization Theory, Industrial \& Corporate Change, Vol. 2 Issue 2 (1993), pp. 107-156.

5. O. Williamson, The Mechanism of Governance (Oxford Univ. Press, New York, 1996).

6. O. Williamson, Transaction cost economics: How it works; Where it is headed, De Economist (0013-063X); Vol. 146 Issue 1 (Apr 1998), pp. 23-59.

7. O. Williamson, The Institutions of Governance, American Economic Review, Vol. 88 Issue 2( May 1998), pp. 75-79.

8. O. Williamson, Strategy Research: Governance and Competence Perspectives, Strategic Management Journal, Vol. 20 Issue 12 (Dec 1999), pp. 1087-1108. 
9. O. Williamson, The New Institutional Economics: Taking Stock, Looking Ahead, Journal of Economic Literature, Vol. 38 Issue 3 (Sep 2000) p. 599.

10. O. Williamson, The Theory of the Firm as Governance Structure: From Choice to Contract, Journal of Economic Perspectives, Vol. 16 Issue 3 (Summer 2002), pp. 171-195.

11. O. Williamson, Examining Economic Organization through the Lens of Contract, Industrial \& Corporate Change, Vol. 12 Issue 4 (Aug 2003), pp. 917-942.

12. O. Williamson, Transaction cost Economics and Business administration, Scandinavian Journal of Management, Vol. 21 Issue 1 (Mar2005), pp. 19-40.

13. Oliver. Williamson, The Economics of Governance, American Economic Review, Vol. 95 Issue 2 (May 2005), pp. 1-18.

14. Ronald. Coase, The Nature of the Firm, Economics, Vol. 4 (1937), pp. 386-405.

15. Ronald. Coase, The Problem of Social Cost, Journal of law and Economics, Vol. 3 (1960), pp. 1-44.

16. Oliver. Williamson, Strategy Research Governance and Competence Perspectives, Book chapter of Competence, Governance \& Entrepreneurship (2000), p26.

17. Paul. Timmers, Business Models for Electronic Markets, Journal on Electronic Markets, Vol. 8 Issue 2 (1998), pp. 3-8.

18. Paul. Bambury, A taxonomy of Internet Commerce, First Monday, Vol. 10 Issue 3 (1998).

19. Allan. Afuah and Christopher. Tucci, Internet Business Models and strategies, text and case (McGraw Hill, Boston, 2001).

20. Magali Dubosson-Torbay, E-Business Model Design, Classification and Measurements, Thunderbird International Business Review, Vol. 4 (2001).

21. Peter Weil, Place to space: Migrating to E-Business Models (Harvard Business School Press, Boston, 2001).

22. B. Mahadevan, Business Models for Internet Based E-Commerce an anatomy, California Management Review, Vol. 42 Issue 4 (2000).

23. B. Klein, R. Crawford and A. Alchian, Vertical Integration, Appropriable Rents and Competitive Contracting Process, Journal of Law and Economics, Vol. 21 (1978), pp. 297-326. 24. B. Klein and K. Murphy, Vertical Restraints as Contract Enforcement Mechanisms, Journal of Law and Economics, Vol. 31 (1988), pp. 265-297.

25. O. Williamson, Asset Specificity and Economic Organization, International Journal of Industrial Organization, Vol. 3 Issue 4 (Dec 1985), pp. 365-379 